\title{
A STUDY- ELECTROCARDIOGRAPHIC AND ECHOCARDIOGRAPHIC CHANGES IN PATIENTS WITH CHRONIC OBSTRUCTIVE AIRWAYS DISEASE
}

\author{
M. N. Lakshmikanth Reddy', Irfan Ahamed H. B2, Mehboob M. Kalburgi' ${ }^{3}$, Mohammed Ismail ${ }^{4}$, Syed Aman Jagirdar ${ }^{5}$
}

${ }_{1}^{1}$ Assistant Professor, Department of Medicine, Al-Ameen Medical College, Bijapur.

${ }^{2}$ Assistant Professor, Department of Medicine, Al-Ameen Medical College, Bijapur.

3 Professor, Department of Medicine, Al-Ameen Medical College, Bijapur.

${ }_{4}^{4}$ Postgraduate Student, Department of Medicine, Al-Ameen Medical College, Bijapur.

5 Postgraduate Student, Department of Medicine, Al-Ameen Medical College, Bijapur.

\section{ABSTRACT}

\section{BACKGROUND}

Chronic obstructive airways disease is known to cause airflow limitation, impaired gas exchange and increased pulmonary arterial pressure. The prevalence of pulmonary hypertension in COAD is 18\%. Increased pulmonary arterial pressure is a predictor of mortality in COAD.

This study aims at analysing various CVS manifestations of COAD with the help of ECG and ECHO.

\section{MATERIALS AND METHODS}

The study was conducted on 100 patients in Al-Ameen Medical College Hospital and Government General Hospital, Bijapur with complaints of persistent cough with expectoration for 3 months for 2 consecutive years or who have cough, breathlessness with clinical/x-ray evidence of hyperinflation between the period of Dec 2010 to July 2012. All patients were subjected to investigations like spirometry, ECG and ECHO according to guidelines.

\section{RESULTS}

In our study $60 \%$ of patients are aged $<50,98 \%$ are males, $2 / 3^{\text {rd }}$ are manual labourers and $3 / 4^{\text {th }}$ are from low socioeconomic status; $46 \%$ of patients had ECG evidence, whereas $44 \%$ had ECHO evidence of pulmonary hypertension. There was a definite correlation between smoking and intensity of smoking with ECHO evidence of pulmonary hypertension [P: 0.001, significant].

\section{CONCLUSION}

In our study, COAD is most common in males with smoking being the principal cause. Severity of disease is directly proportional to intensity of smoking and most patients are from low socioeconomic status. ECG has high sensitivity in detecting pulmonary hypertension in COAD patients, which was confirmed by ECHO.

\section{KEYWORDS}

COAD, ECG, ECHO, Reid Index, Pulmonary Hypertension.

HOW TO CITE THIS ARTICLE: Reddy MNL, Ahamed IHB, Kalburgi MM, et al. A study- electrocardiographic and echocardiographic changes in patients with chronic obstructive airways disease. J. Evolution Med. Dent. Sci. 2017;6(5):430-434, DOI: $10.14260 /$ Jemds/2017/95

\section{BACKGROUND}

Chronic Obstructive Airways Disease is acknowledged by the "WHO" as the fourth commonest cause of death worldwide. It is projected to be the third most common cause of death and fifth most common cause of chronic disability by the Year 2020.

Earlier in the $20^{\text {th }}$ century, TB was the major pulmonary disease in developing countries. Its place has been taken by two diseases in the later half of 20th century, namely chronic obstructive airways disease and carcinoma of lung.[1]

Cigarette smoking is said to have been playing a major role in the aetiology of Chronic Obstructive Airways Disease. Knowing the ill effects of smoking, many Governments including Indian Government have banned smoking in public

Financial or Other, Competing Interest: None.

Submission 10-12-2016, Peer Review 04-01-2017,

Acceptance 09-01-2017, Published 16-01-2017.

Corresponding Author:

Dr. Irfan Ahamed H. B,

S/o. K. B. Basheer Ahamed,

$1^{\text {st }}$ Stage, $2^{\text {nd }}$ Cross, Door \#15, Iqbal Manzil,

Dr. Ram Manohar Lohiya Nagar,

Shimoga-577201, Karnataka.

E-mail:dr.irfan28@gmail.com

DOI: $10.14260 /$ jemds $/ 2017 / 95$

\section{(c) $(1) \ominus$}

places. This may in future lead to reduction in number of smokers and its ill effects, thus reducing the incidence of COAD in due course.

Chronic Obstructive Airways Disease is known to cause airflow limitations, impaired gas exchange and increased pulmonary artery pressure. According to literatures, prevalence of pulmonary hypertension in chronic obstructive airways disease is $18 \% .{ }^{1}$ Elevated pulmonary artery pressure is a predictor of mortality in chronic obstructive airways disease. "Weitzenblum" and coworkers ${ }^{2}$ showed a 72\% 4year survival in patients with normal pulmonary artery pressure compared with $49 \%$ survival in patients with an elevated pulmonary artery pressure in Chronic Obstructive Airways Disease.[2]

Both electrocardiography and echocardiography are very useful in the detection of elevated pulmonary artery pressure. Here, an attempt has been made to correlate clinical features, pulmonary function tests, electrocardiography and echocardiography in case of Chronic Obstructive Airways Disease patients.

WHO/National Heart, Lung and Blood Institute GOLD (Global Initiative for Chronic Obstructive Lung Disease) Chronic Obstructive Airways Disease is a disease state characterised by airflow limitation that is not fully reversible. 
The airflow limitation is usually both progressive and associated with an abnormal inflammatory response of the lungs to noxious particles and gases.[3]

\section{Chronic Bronchitis}

Chronic bronchitis is defined epidemiologically as a condition in which persistent cough with sputum production is present for at least 3 months for 2 consecutive years. Prognosis is linked to the presence of airflow obstruction and not sputum production. ${ }^{4]}$

\section{Emphysema}

Emphysema is defined pathologically as an abnormal permanent dilatation of air spaces distal to the terminal bronchiole accompanied by destruction of the alveolar walls without obvious fibrosis.[5]

\section{Aetiology of Chronic Obstructive Airways Disease}

1. Tobacco use and cigarette smoking (active and passive) major risk factors; $15 \%$ of smokers develop COAD.

2. Genetic: Alpha 1 antitrypsin deficiency.

3. Respiratory disease of prematurity, chronic untreated asthma, childhood malnutrition and low birth weight may play a role.

4. Occupational hazards such as toluene diisocyanate, coal dust (mine field workers) and redwood cedar. Occupational dusts appear to be most significant.[6]

5. Indoor pollution, particularly cooking performed in poorly ventilated homes.

6. Bronchial hyperresponsiveness - (Dutch hypothesis).

7. Infections - (British hypothesis).

8. Low socioeconomic status.[7]

\section{Reid Index}

The ratio of the thickness of the submucosal glands to that of the bronchial wall is expressed as Ried index.

- In normal individuals, it is $0.44+0.09$.

- In chronic bronchitis, it is $0.52+0.08$.

If the submucosal layer thickness is $>50 \%$ of bronchial wall thickness, it is highly suggestive of chronic bronchitis. High index is commonly associated with symptoms. ${ }^{[8]}$

\section{Pulmonary Vascular and Cardiac Changes}

There is inflammation in the pulmonary arteries even in early Chronic Obstructive Airways disease like that occurring in the adjacent airways. In severe cases thickening of arterial smooth muscle and reduplication of elastic lamina with extensive pulmonary arterial wall remodeling are present. In patients with persistent daytime arterial hypoxaemia secondary to Chronic Obstructive Airways Disease in right ventricular mass is increased. The extent of right ventricular hypertrophy is not however related to pulmonary arterial pressure measured in vivo, rather it is correlated with the baseline $\mathrm{PaO} 2$ experienced during the last year. There is hypertrophy of carotid bodies and increase in the size of glomerular tuft. $[9,10]$

\section{Electrocardiographic Findings in Chronic Obstructive Airways Disease.}

- P pulmonale - P wave amplitude $>2.5 \mathrm{~mm}$ in standard leads together with right $\mathrm{p}$ wave axis.
- Right QRS axis deviation directed to the region of +90 degrees clockwise to +150 degrees.

- Left QRS axis deviation in $10 \%$ of cases.

- SI, SП, SШ syndrome - prominent S waves in standard leads I, $\Pi$ and Ш. This indirectly reflects posterior displacement of the apex. Rather wide and slurred $S$ wave may appear in all three standard leads and leads V4 to V6.

- Complete/incomplete right bundle branch block.

- $\mathrm{R} / \mathrm{S}>1$ in $\mathrm{V} 1$ or $\mathrm{R}$ wave amplitude in $\mathrm{V} 1>5 \mathrm{~mm}$.

- $\mathrm{R} / \mathrm{S}<1$ in $\mathrm{V} 6$ or $\mathrm{R}$ wave in $\mathrm{V} 6<5 \mathrm{~mm}$, transition zone is frequently displaced to lead V6 or even further to left.

- Small QS or W shaped complexes in right precordial leads.

- Diminution of QRS magnitude in all the precordial leads. Small $\mathrm{R}$ waves may completely disappear in right precordial leads.

- $\mathrm{T}$ wave - decrease in amplitude in all leads may be inverted in right precordial leads.[11]

Echocardiographic Findings of Pulmonary Hypertension in Chronic Obstructive Airways Disease

- Increased pulmonary artery pressure.

- Tricuspid regurgitation.

- Right ventricular wall thickening.

- Increased right ventricular volume.

- Reversed movement of the interventricular septum.

- Enlargement of right atrium and ventricle.

- Normal or small left ventricular dimensions. Echocardiographic findings that portend a poor prognosis include pericardial effusion, right atrial enlargement and septal displacement.[12]

\section{Aim of the Study}

To analyse various cardiovascular manifestations of "Chronic Obstructive Airways Disease" with the help of Electrocardiography and Echocardiography.

\section{MATERIALS AND METHODS \\ Materials and Methodology \\ Population}

Patients attending the outpatient clinic and who were admitted in "Al-Ameen Medical College Hospital and Government Hospital, Bijapur" with complaints of persistent cough with expectoration for 3 months in two consecutive years or who have cough, breathlessness with clinical or $\mathrm{x}$ ray evidence of hyperinflation were selected for the study (100 patients).

\section{Period of the Study}

January 2010 - July 2012.

\section{Inclusion Criteria}

Patients with spirometric evidence of chronic obstructive airways disease. Criteria for diagnosis of chronic obstructive airways disease - FEV1 < 80\% predicted value and FEV1/FVC $<70 \%$.

\section{Exclusion Criteria}

Patients with TB, bronchial asthma, bronchiectasis, bronchogenic carcinoma, interstitial lung disease, coronary artery heart disease, systemic hypertension, aortic and mitral valve disease, right heart failure and patients residing at high altitude were excluded from the study by doing x-ray chest, 
Mantoux test, sputum for acid fast bacilli and blood pressure measurement.

\section{Performance of Spirometry}

Spirometry was done according to the guidelines published by both the British Thoracic Society (BTS) with the Association of Respiratory Technicians and Physiologists (ARTP) and the American Thoracic Society. According to these guidelines production of reliable results of spirometry is very dependent on the person performing the test. They must have the ability to encourage the patients to perform a maximal forced exhalation. The patients were demonstrated the manoeuvre first. They were seated in a comfortable stool. They were asked to take deep full inspiration. Good seal was maintained with the mouth piece of spirometry. With maximum effort, exhalation was continued for at least 6 seconds and to. a maximum of 15 seconds. The results of the measurement were accepted only if the trace is smooth and cough free. The manoeuvres were done thrice for each patient and the best FEV1 and the best FVC were recorded. Reversibility test with inhaled salbutamol was done to rule out bronchial asthma (reversibility more than 15\%). ECGs were taken and coronary artery heart disease was ruled out.

ECG Evidence of Pulmonary Hypertension in Chronic Obstructive Airways Disease -

- P pulmonale.

- Right QRS axis deviation.

- $\quad$ SI, SП, SШ syndrome.

- Diminution of QRS magnitude in all the precordial leads.

- $\mathrm{R} / \mathrm{s}>1$ in $\mathrm{V} 1$ or $\mathrm{R}$ wave amplitude in $\mathrm{V} 1>5 \mathrm{~mm}$.

- $\mathrm{R} / \mathrm{s}<1$ in V5 or V6 or R wave in V6 $<5 \mathrm{~mm}$.

- Complete/incomplete right bundle branch block.

- Echocardiographic evidence of pulmonary hypertension in COAD.

- Enlargement of right atrium and ventricle.

- Normal or small left ventricular dimensions.

- Thickened interventricular septum.

- Reversed septal motion.

- Tricuspid regurgitant velocities - contrast enhancement with saline improves accuracy.

Doppler Echocardiographic quantification of right ventricular systolic hypertension can be obtained by measuring the velocity of the tricuspid regurgitant jet and using the Bernoulli formula.

\section{OBSERVATIONS AND RESULTS}

\section{Age Distribution}

Chronic obstructive airway disease is most prevalent in persons aged $<50$ years, i.e. $60 \%$ of patients are $<50$ years of age.

\section{Sex Distribution}

Chronic obstructive airways disease is most prevalent in males.

\section{Smoking Pattern}

$72 \%$ of COAD patients are smokers; $83 \%$ smokers (60 Persons) still continue to smoke.

\section{Smoking Intensity}

$64 \%$ of smokers smoke $<10$ cigarettes per day; $19 \%$ of smokers smoke more than 20 cigarettes per day.

\begin{tabular}{|c|c|c|}
\hline ECG Findings & Frequency & \% \\
\hline P pulmonale & 34 & 34 \\
\hline QRS Right Axis Deviation & 28 & 28 \\
\hline Right Bundle Branch Block & 12 & 12 \\
\hline R/s > 1 in V1 & 8 & 8 \\
R/s < 1 in V6 & 6 & 6 \\
\hline $\begin{array}{c}\text { Poor progression of R wave in right } \\
\text { precordial leads }\end{array}$ & 10 & 10 \\
\hline $\begin{array}{c}\downarrow \text { T-wave amplitude in right } \\
\text { precordial leads }\end{array}$ & 4 & 4 \\
\hline \multicolumn{2}{|c|}{ Table 1. Interpretation of ECG } \\
\hline \multicolumn{2}{|c}{} \\
\hline
\end{tabular}

\begin{tabular}{|c|c|c|c|}
\hline \multirow{2}{*}{ ECG Evidence of PHT } & \multicolumn{2}{|c|}{ ECHO Evidence of PHT } & \multirow{2}{*}{ Total } \\
\cline { 2 - 3 } & Absent & Present & \\
\hline Absent & 36 & 10 & 46 \\
\hline Present & 8 & 46 & 54 \\
\hline Total & $\mathbf{4 4}$ & $\mathbf{5 6}$ & $\mathbf{1 0 0}$ \\
\hline Table 2. ECG Evidence ${ }^{*}$ ECHO Evidence of PHT \\
\hline
\end{tabular}

$\mathrm{P}$ - Not significant.

Pulmonary artery catheterisation is the gold standard for measurement of pulmonary artery pressure. If we take Doppler echocardiogram measurement of pulmonary arterial pressure as the standard procedure, sensitivity and specificity of ECG evidence of pulmonary hypertension can be measured by Wilson score.

\section{Echo Changes in COPD}

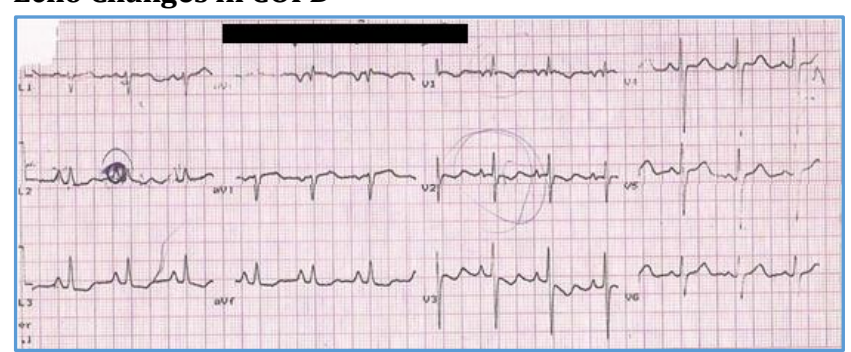

Figure 1. ECG showing P Pulmonale, Right Axis Deviation, $R V H$ with Strain $(R / S>1$ in $V 1, R / S<1$ in $V 5, V 6), Q R$ in $A V R, Q R$ in V1 (Right Atrial Enlargement)

\section{Echo Changes in COPD}

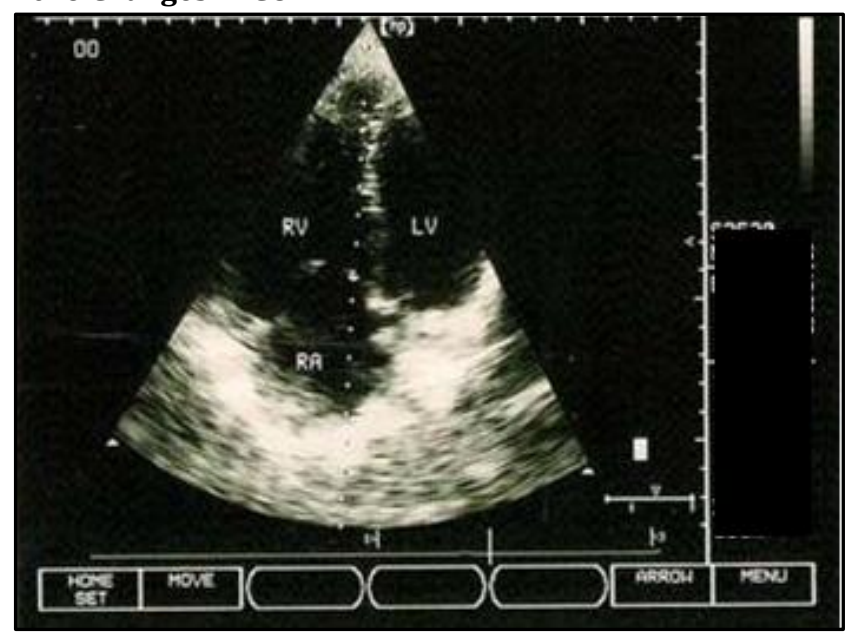

Figure 2. Echo showing Right Atrial and Right Ventricular Dilatation in a COAD Patient 


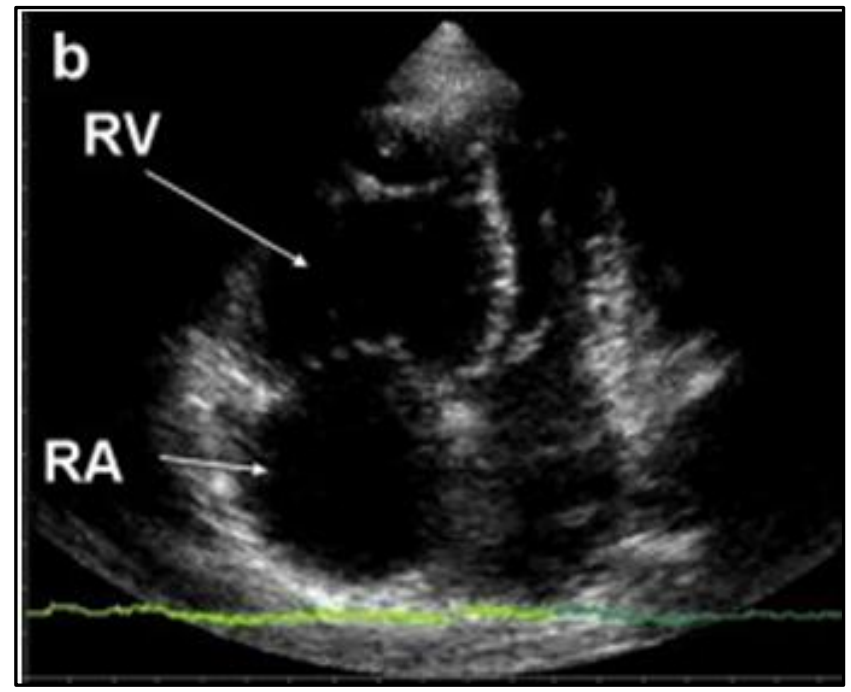

Figure 3. Echo showing Right Atrial and Right Ventricular Dilatation in a COAD Patient

\section{DISCUSSION}

In our study, chronic obstructive airways disease is present almost exclusively in males. This is due to increased prevalence of smoking in males. According to literatures after standardisation for smoking males are at high risk than females.[13]

Most of the chronic obstructive airways disease patients start smoking at an earlier age, especially in teen years. Normally, lung growth is maximal by the late teenage years and lung function is relatively constant until the late 20 s. Smoking teenagers do not achieve the peak value of their non-smoking contemporaries and begin to lose lung function as soon as growth ceases. ECG and ECHO evidence of pulmonary hypertension is more common in smokers who smoke more than 20 cigarettes/day than those smoke less or those who do not smoke. The role of smoking in the pathogenesis of chronic obstructive airways disease received considerable attention in the 1960s.

Studies involving ECG evidence of pulmonary hypertension in COAD patients. According to literatures many patients have ECG changes suggestive of RV strain, but did not manifest RV strain by Echocardiography. Fishman standard criteria for right ventricular hypertrophy in ECGs were absent in $2 / 3^{\text {rd }}$ of chronic obstructive airways disease patients who had right ventricular hypertrophy on postmortem examination.[14] ECG of prognostic importance in severe chronic obstructive airways disease has been outlined by Kok-Jensaw.[15] In a study of 288 patients, survival was very poor in individuals with a QRS axis of +90 degrees to +180 degrees and amplitude of $\mathrm{P}$ wave in lead $\Pi$ of $2 \mathrm{~mm}$ or more. Only $37 \%$ and $47 \%$ respectively of patients with these changes were alive after 4 years. In V. K. Singh and S. K. Jain study of 130 patients of chronic obstructive airways disease effect of airflow obstruction on ECG findings such as $\mathrm{p}>2.5$ $\mathrm{mm}, \mathrm{QRS}$ axis equal or more than +90 degrees, $\mathrm{R}$ wave in $\mathrm{V} 6$ less than or equal to $5 \mathrm{~mm}, \mathrm{R} / \mathrm{S}$ ratio in $\mathrm{V} 5$, V6 equal to or less than 1 shows a negative correlation with FEV1/FVC ratio. Other features like T wave amplitude, negative "p" wave in avL, S wave more than $5 \mathrm{~mm}$ in depth in V5, V6 and SI, SП, SШ patterns were observed less frequently and correlate weakly with severity of disease. In a study involving 50 plantation workers attending General Hospital, Tata Tea Ltd., Munnar,
Kerala, good correlation between severity of COAD and number of abnormal ECG manifestations was present. In a case control study involving 50 cases and 50 controls age and sex matched ECG features of RAD and RV strain, and ECHO features of right chambers and pulmonary artery enlargements were compared. According to the study, sub clinical cor pulmonale and severity of right-sided haemodynamic disturbances can be measured accurately.[16]

In a study involving 25 COAD patients of R G Kar Medical College, Calcutta, ECG and ECHO findings were compared. ECG evidence of RVH i.e. P pulmonale, right axis deviation, RBBB, clockwise rotation was present in $50 \%$ of patients. ECHO evidence of right ventricular hypertrophy and elevated pulmonary artery pressure were found in $85 \%$ of cases. In our study, $44 \%$ of patients have ECHO evidence of elevated pulmonary artery pressure; 4 patients had right atrial dilatation; 1 patient had pericardial effusion. Both right atrial enlargement and pericardial effusion show poor prognosis.

\section{CONCLUSION}

- In our study, chronic obstructive airways disease is more common in males.

- Smoking is the principle cause of chronic obstructive airways disease.

- Severity of chronic obstructive airways disease is directly proportional to intensity of smoking.

- Severity of chronic obstructive airways disease is associated with earlier age of onset of smoking, especially in teen ages.

- Most patients are in low socioeconomic status.

- Electrocardiography has high sensitivity in detecting pulmonary hypertension in chronic obstructive airways diseased patients as evidenced by $\mathrm{P}$ pulmonale, right axis deviation, right ventricular hypertrophy. Majority of the patients with electrocardiographic evidence of pulmonary hypertension also had echocardiographic evidence of elevated pulmonary artery pressure. So both electrocardiography and echocardiography are very useful in the assessment of severity of chronic obstructive airways disease.

\section{REFERENCES}

[1] Arcasoy SM, Christie JD, Ferrari VA, et al. Echocardiographic assessment of pulmonary hypertension in patients with advanced lung disease. Am J Respir Crit Care Med 2003;67(5):735-40.

[2] Weitzenblum E, Hirth C, Ducolone A, et al. Prognostic value of pulmonary artery pressure in COPD. Thorax 1981;36(10):752-8.

[3] Hogg JC. Bronchiolitis in asthma and chronic obstructive pulmonary disease. Clinical Chest Med 1993;14(4):73340.

[4] Snider GT, Kleinerman J, Thurlbeck WM. The definition of emphysema. Report of NHLBI, division of lung disease workshop. Am Rev Respir Dis 1985;132(1):1825 .

[5] Laurell CB, Erickson S. The electrophorectic alpha 1 globulin pattern of serum in alpha 1 antitrypsin deficiency. Scand J Clin Lab Invest 1963;15:132-40.

[6] MacNee W. Oxidants/antioxidants and COPD. Chest 2000;117(5 Suppl 1):303S-17S. 
[7] Lamb D. Pathology. In: Calverley P, Pride N, (eds) Chronic obstructive pulmonary disease. London: Chapman and Hall, 1995:9-34.

[8] Doll R, Peto R, Wheatley K, et al. Mortality in relation to smoking: 40 years observation on male British doctors. BMJ 1994;309(6959):901-11.

[9] Costello R, Deegan P, Fitzpatrick M, et al. Reversible hypercapnia in COPD: a distinct pattern of respiratory failure with a favorable prognosis. Am J Med 1997;102(3):239-44.

[10] Jorenby DE, Leischow SJ, Nides MA, et al. A controlled trail of sustained release bupropion, a nicotine batch or both for smoking cessation. $\mathrm{N}$ Engl J Med 1999;340(9):685-91.

[11] Galie N, Torbicki A, Barst R, et al. Guidelines on diagnosis \& treatment of pulmonary arterial hypertension. The task force on diagnosis and treatment of pulmonary arterial hypertension of the european society of cardiology. Eur Heart J 2004;25(24):2243-78.
[12] Oswald-Mammosser M, Oswald T, Niyankiye E, et al. Non invasive diagnosis of pulmonary hypertension in COPD. Comparison of ECG, radiological measurements, ECHO \& myocardial scintigraphy. Eur J Respir Dis 1987;71(5):419-29.

[13] Naeije R, Torbicki A. More on the diagnosis of PHT: doppler echocardiography revisited. Eur Resp J 1995;8(9):1445-9.

[14] Fisher MR, Criner GJ, Fishman AP, et al. Estimating pulmonary artery pressure by ECHO in patients with emphysema. Eur Respir J 2007;30:914-21.

[15] Buzkanat E, Tozkoparan E, Baysan 0, et al. The significance of elevated brain natriuretic peptide levels in COPD. J Int Med Res 2005;33(5):537-44.

[16] McGoon M, Gutterman D, Steen V, et al. Screening, early detection \& diagnosis of pulmonary arterial hypertension: ACCP evidence based clinical practice guidelines. Chest 2004;126(Suppl 1):14S-34S. 